\section{AKADEMOS}

Órgano de difusión de la Red Docencia-Investigación

\section{ISSN: $1995-4743$}

Año 14 Vol. 1,n. 34 Enero-Junio 2020

AKADEMOS es una revista semestral. De amplio espacio editorial, para la publicación de trabajos inéditos de investigación, artículos de análisis, reseñas y opinión, en los distintos tópicos de las ciencias, la tecnología, las artes y la cultura.

\title{
El concepto de hermenéutica
}

\section{David E. López}

Dr. en Filosofía, Investigador del Centro de Investigaciones en Ciencias y

Humanidades (CICH), Universidad Dr. José Matías Delgado

davidelopez@hotmail.com

\section{Fecha de recepción 30/01/2020 • Fecha de aceptación 28/03/2020}

\section{Resumen}

El concepto de hermenéutica ha sufrido una evolución desde la antigüedad clásica hasta nuestros días, pasando de significar interpretación, explicación, traducción o comprensión, en sentido amplio, hasta llegar a concebirse como un modo de comprender un texto del pasado producido en una situación cultural y espacio temporal distinta de la del lector, con énfasis especial en el texto sacro. Uno de los momentos fuertes del concepto es su acepción filosófica y literaria: la hermenéutica como un modo histórico y actualizado, siempre abierto, de leer el texto y de ser comprendidos por él, y un modo de ser que se realiza en el lenguaje. Poca fuerza han tenido los enfoques que sostienen que la hermenéutica es un método para obtener conocimiento.

\section{Abstract}

The concept of Hermeneutics has undergone an evolution since classical times until our days, coming from its pristine meaning as interpretation, explanation, translation or understanding, in a wide sense, to its development as a way of understanding a text of the past, carried out in a cultural, tempo- 
ral and spacial context quite different from that of the nowadays reader. Its textual paradigm is the sacred text. One of the higher meaning of the concept of Hermeneutics is its philosophical and litterary sense is this: Hermeneutics as historical, actualized and open manner of Reading a text and been understood by it, and a way of Being which is carried out in the language. Less striking is the understanding of Hermeneutics as a method of reaching knowledge.

Palabras clave: hermenéutica, interpretación, comprensión, traducción, exégesis, lenguaje, lingüisticidad, método, ciencias del espiritu, tradición.

Key Words: Hermeneutics, Interpretation, Understehen, Translation, Exegesis, Language, linguistic Essence (Sprachlichkeit), Method, Humanities, Tradition.

\section{Introducción a la hermenéutica}

Uno de los más destacados estudiosos de la historia de la hermenéutica en lengua inglesa es el estadounidense Richard Palmer, quien inicia su introducción con unas palabras que todavía hoy, luego de 50 años de aquella publicación, suenan con igual fuerza: "Hermenéutica es una palabra que se oye cada vez más en círculos teológicos, filosóficos e incluso literarios." (Palmer, 1968, p. 19)

A las palabras anteriores de Palmer habría que agregar que hermenéutica suena con igual o más fuerza en círculos religiosos de los tipos más variados y también en numerosos manuales de metodología de la investiga- ción, y que la confusión acerca de la misma no es de poca cuantía.

Debido a lo anterior, comenzaremos nuestro estudio con un análisis del término y algunos de los usos más primitivos que nos son posibles rastrear.

\section{La familia de palabras ligadas al

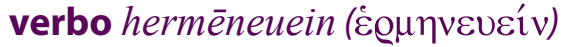

Existe una familia de palabras que comparte el tema hermēn-: en primer lugar tenemos el

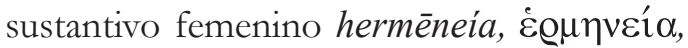
(variantes: hermèneutikè y hermēnía, Bauer, 1979, p. 310), que es atestiguado en el periodo presocrático (Bauer, 1979, p. 310), y que suele hacerse equivaler por traducción $\mathrm{O}$ interpretación (Palmer, 1968, 28). Pero este sustantivo tiene otros usos registrados: en Epicuro se usa especialmente en el sentido de interpretación o explicación, especialmente referido a la explicación del pensamiento mediante la palabra. En Platón, concretamente en el Epinomis, indica meditación. (Liddell and Scott, 1968, p. 690)

Heródoto, en sus Nueve libros de la bistoria, del siglo $\mathrm{V}$ a.C, refiere un significado muy concreto: traducción de una lengua extranjera. Y de ahí que el sustantivo hermēneus

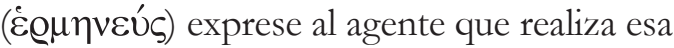
traducción: el traductor o intérprete. (Liddell and Scott, 1968, p. 690)

Hermēneus (traductor o intérprete) tiene, además, otros significados más profanos, los que encontramos sobre todo en el griego helenista o el así llamado koiné, atesti- 
guado en numerosos papiros. Dos de estos significados son especialmente relevantes: el primero se refiere al mediador o intermediario en las relaciones amorosas, que lo podríamos traducir por agente matrimonial o mediador amoroso, en todos los sentidos posibles del término, uso que indica algo del cómo se establecían las relaciones amorosas en el mundo helenista, que en ocasiones hacía necesario un mediador. El segundo significado profano de hermēneus se refiere a las actividades económicas, ya que el sustantivo se refiere a un tipo de individuo, al comerciante, intermediario o comisionista en una transacción comercial.

Estudiemos el verbo hermēneuein, que está atestiguado desde Platón en Ilión o de la poesía, en la Septuaginta (especialmente en Job 42,17), en Flavio Josefo y en el Nuevo Testamento, entre otros lugares, y básicamente significa traducir e interpretar (Platón, Ilión), específicamente, traducir una lengua extranjera; pero también explicar o exponer un asunto, como en Job 42,17. En estos casos también expresa la idea de mediar para hacer comprender o inteligir.

El sustantivo masculino hermēneutēs, sinónimo de hermēneus, atestiguado en Platón y en Polibio; y también en la literatura judeohelenista y cristiana: en la Septuaginta y en Papías, para mencionar algunos casos. Este sustantivo significa traductor, y así aparece en Gen 42, 23 y en 1Cor 14,28. Llama la atención el hecho de que en el cristianismo primitivo se le llame a San Marcos, el evangelista, el intérprete o traductor de Pedro, dando a entender con ello que Pedro no hablaba la lengua griega o, en el mejor de los casos, que sus palabras debían hacerse comprensibles a sus oyentes a través de un mediador.

Observemos algunos detalles del uso en la lengua griega de algunas de estas palabras.

A propósito de hermēnía, Palmer (1968) sostiene que la palabra aparece en forma de sustantivo en Edipo en Colona y varias veces en Platón. También se encuentra en escritores antiguos como Jenofonte, Plutarco, Eurípides, Epicuro.

A esta familia habría que agregar al menos dos palabras: 1) hermēneios, sustantivo masculino que se refiere al mediador y también al sacerdote (Palmer, 1968, p. 30), y a 2) hermēs, el nombre propio del dios de la mitología griega, mensajero de los dioses, hijo de Zeus y de Maia, cuyos relatos más antiguos los encontramos en la Odisea y en la Teogonía, de Hesíodo. Hermes es el dios que interpreta y hace comprensibles los oráculos divinos a los hombres, mediación sin la cual la palabra divina sería incomprensible o enigmática. Esos dos últimos vocablos relacionados con hermenéutica Palmer (1968) los explica de esta manera:

La palabra griega hermēneios se refiere al sacerdote del oráculo de Delfos. Esta palabra, el verbo hermēneuein y el sustantivo hermēneia hacen referencia al dios mensajero de pies alados Hermes, de cuyo nombre supuestamente se derivan (¿o viceversa?). Significativamente Hermes se asocia con la función de convertir lo que 
está más allá de la comprensión humana en una forma que la inteligencia humana pueda captar. Las distintas formas de la palabra sugieren el proceso de llevar una cosa o situación de la incomprensibilidad a la comprensión. Los griegos atribuyeron a Hermes el descubrimiento del lenguaje y la escritura, herramientas que la inteligencia humana utiliza para captar el significado y transferirlo a otros. (p. 30)

Algunos estudios han afirmado que el verbo hermēneuein y el sustantivo hermēneía podrían derivar del nombre del dios Hermes, dada la función de este último en el panteón griego. Pero esto es muy improbable. No hay evidencia de esta afirmación. Más plausible sería lo opuesto: el nombre del dios deriva del sustantivo hermēneía; esto es, primero surge la actividad de interpretar o mediar la comprensión, y luego un dios especializado en la misma, como es el caso de otras actividades sociales de la antigua Grecia que luego tienen un dios protector.

\section{Una primera aproximación a la hermenéutica}

En toda la familia de palabras que comparten el tema hermèn- aparece un contenido semántico básico: la idea de que algo no es comprensible, y por eso necesita de una interpretación o explicación o, dicho de otra forma, la idea de hacer comprender o de mediar la comprensión. De esta manera, la actividad de traducir implica que algo no se entiende y que hace necesaria dicha acción; igualmente, la idea de interpretar o explicar manifiesta poca claridad de lo dicho, y la necesidad de hacerlo comprensible. Y lo mismo puede decirse del agente de esas acciones: es necesario alguien que medie la comprensión, alguien que haga inteligible algo que no lo es, del mismo modo que lo hacía Hermes con los mensajes divinos, ininteligibles para los mortales, por encontrarse en un mundo distinto.

Por otro lado, la familia de palabras que comparte el tema hermèn- y su significado básico indica algo que será fundamental en todas las direcciones que irá tomando la hermenéutica a lo largo de los siglos, tanto la hermenéutica teológica, literaria o bien filosófica: la interpretación es una actividad social; el individuo solo, aislado, al margen de la sociedad no puede comprender nada por sí mismo, por una especie de iluminación, gracias a una noche mística o a un golpe de suerte. La comprensión es una actividad social, necesita de mediadores y de mediación. Hacer comprender o inteligir a otros el significado profundo de un asunto, sea éste literario, de otras esferas del arte, la comprensión de un texto sacro, de un texto religioso, entre otros, es una actividad comunitaria.

Expresado lo anterior, la hermenéutica tiene mucho que ver con la actividad mediadora de la comprensión, constituyéndose en una especie de puente. Por esta razón, en algún momento la lengua griega identificó al hermeneuta o intérprete como un sacerdote que media entre los dioses y los hombres. De este modo, arribamos a una primera aproximación de la hermenéutica: 
La hermenéutica es el estudio de la comprensión, y sobre todo la tarea de comprender los textos. La ciencia natural dispone de una serie de métodos para comprender los objetos naturales, las 'obras' requieren una hermenéutica, una 'ciencia' de la comprensión adecuada a las obras como obras. No hay duda de que los métodos de 'análisis científico' pueden y deben aplicarse a las obras, pero al hacerlo las obras son tratadas como objetos silenciosos, naturales. En tanto en cuanto éstas son objetos, se les puede tratar con métodos científicos. Como obras requieren formas de comprensión más sutiles y exhaustivas. Como un intento de describir estas últimas, más específicamente 'históricas' y 'humanísticas' formas de interpretación surgió la hermenéutica. (Palmer, 1968, pp. 24-25)

Esta interpretación es fundamentalmente lingüística, como Heidegger (1992) lo hará saber posteriormente en el Ser y el tiempo, dada la lingüisticidad del ser, como el célebre filósofo afirma, lo que también expresa con su célebre aforismo: "El lenguaje es la morada del ser", entendiendo por ello, al menos, que el lenguaje es el espacio donde acontece la experiencia y la comprensión de la misma; que no hay hermenéutica sin lenguaje o, en otros términos, la hermenéutica es lenguaje; en este sentido, el filósofo de Freiburg rechaza la idea del lenguaje concebido como un mero envoltorio de nuestro pensamiento y experiencias, instrumento o vehículo de nuestros pensamientos, tal como se entendió hace algún tiempo. Pero no es cierto que la hermenéutica se reduzca al ámbito del lenguaje, solamente. Para Palmer (1968, p. 26), por ejemplo, "La interpretación abarca mucho más que el mundo lingüístico en el que el hombre vive, ya que incluso los animales viven interpretando. Estos perciben el lugar que ocupan en el mundo.” En el caso del ser humano, continúa, la "Interpretación es la acción más elemental del pensamiento humano.” (p. 25). Y sobre el nivel lingüístico de la interpretación añade:

Constantemente se está tejiendo una interpretación en muchos niveles no lingüísticos del tejido del humano vivir en común. La existencia humana se puede concebir sin lenguaje, observa Joachim Bach, pero no sin la comprensión mutua, esto es, no sin interpretación. Pero la existencia humana tal y como la conocemos siempre implica lenguaje y, por tanto, cualquier teoría de la interpretación humana debe tratar el fenómeno del lenguaje. (Palmer, 1968, p. 26)

Es muy evidente, luego, que la hermenéutica no se reduce al ámbito del lenguaje. Puede haber una hermenéutica de la pintura, de la arquitectura, entre otros; pero su espacio vital es el lenguaje, visto que el lenguaje " $\mathrm{Da}$ forma a la visión y al pensamiento del hombre, tanto su concepción de sí mismo como de su mundo (no están tan separados como pueda parecer). Su visión de la realidad se moldea mediante el lenguaje. El hombre canaliza las diferentes facetas de su existencia (sus rezos, forma de amar, comportamiento social, pensamiento abstracto) mediante el lenguaje mucho más de lo que se imagina. Incluso sus sentimientos adquieren forma 
a través del lenguaje. Si profundizamos el tema, nos daremos cuenta de que el lenguaje es el 'medio' en el que vivimos, nos movemos y existimos." (Palmer, 1968, p. 26)

Una manera posible de entender la hermenéutica es pensarla como un análisis de un texto, sea éste antiguo o moderno; realizar un trabajo de disección, como si se tratase de un insecto o de un cadáver. De este modo, hacer hermenéutica equivaldría a diseccionar el texto. Hacer hermenéutica, ciertamente, supone el análisis, la crítica del texto, la exégesis del escrito. Sin este análisis lingüístico no sería posible hacer una hermenéutica: cualquier cosa que se dijera sería vacía, sería un mero decir 'yo siento', 'yo creo', 'yo percibo', 'esto me golpea'. De esta manera haríamos decir al texto lo que nosotros queremos que diga, insertaríamos en él nuestras preocupaciones e intereses; no escucharíamos lo que el texto dice. El análisis nos pone en guardia, como dice Gadamer (1999), contra de las trampas de nuestro entendimiento. Luego de ello, hacer hermenéutica no es igual a hacer un análisis, y así lo reitera Palmer (1968, p. 27): un problema de los críticos literarios es igualar 'análisis e interpretación'. Y añade:

Una obra literaria no es un objeto que comprendemos mediante su conceptualización o análisis, es una voz que debemos oír y a través de la 'escucha' (más que mediante la percepción) comprenderla. Como se indica en capítulos sucesivos, la comprensión es un fenómeno epistemológico y ontológico. La comprensión de la literatura debe enraizarse en los mo- dos más primarios y generales de comprensión que tienen que ver con nuestra existencia. Por tanto, comprender una obra literaria no es una forma científica de conocer que se escapa de la existencia y vuela a un mundo de conceptos, es un encuentro histórico al que da lugar la experiencia personal de estar aquí en el mundo. (Palmer, 1968, p. 27)

Visto lo anterior, podríamos decir que la hermenéutica es un modo más global o holístico de acercarnos al texto o al objeto de estudio como 'obra', pero que esta visión más global o complexiva no puede llevarse a cabo sin el análisis. Y a partir de lo expresado, el autor nos da una nueva aproximación a la hermenéutica:

La hermenéutica es el estudio de esta última forma de comprensión. Intenta unir dos áreas de la teoría de la comprensión: qué es lo que implica el hecho de comprender un texto y qué es la comprensión en sí misma en su sentido más fundamental y 'existencial'. (Palmer, 1968, p.27)

En consecuencia de lo anterior, la teoría hermenéutica no considera el texto como un 'objeto' a diseccionar, sino que lo considera como 'obra', como algo a través de lo cual el autor habla, se comunica, nos dice algo sobre el mundo y sobre su mundo, y ese 'algo' tiene mucho que decirnos hoy a nosotros como lectores; pero ese 'algo' necesita de un lector que lo comprenda, -sin lector el texto muere- pero este comprender no es inmediato: hay una distancia cultural, temporal, lingüística, espacial; en fin, el mundo del autor y de 
la obra son distintos del mundo del lector. Por eso, Palmer 1968 enfatiza:

La hermenéutica, cuando se define como la interpretación de las obras del hombre, trasciende las formas lingüísticas de la comprensión. Sus principios se aplican no solo a las obras escritas sino también a cualquier obra de arte. A partir de aquí, la hermenéutica es fundamental para todas las humanidades, que son todas aquellas disciplinas que se ocupan de la interpretación de las obras del hombre. (Palmer, 1968 , p. 27

A manera de resumen de los aspectos filológicos del concepto, Palmer (1968, p. 30) expresa que a partir de la raíz de la palabra hermenéutica y sus términos relacionados, se puede afirmar lo siguiente: "Los orígenes de las palabras modernas 'hermenéutica' y 'hermenéutico' sugieren el proceso de 'llevar a la comprensión', sobre todo porque este proceso implica al lenguaje, ya que el lenguaje es el medio por excelencia en este proceso." A continuación sostiene que existen tres direcciones básicas de significado de las palabras hermēneuein y hermēneía en su uso antiguo, los cuales son: 1) expresar en voz alta en palabras o 'decir', 2) explicar, como en la explicación de una situación, y 3) traducir, como en la traducción de un idioma extranjero. (Palmer, 1968, pp. 30-31).

De paso debemos decir, con Cuestas Abad (1991, p. 16), que la traducción latina del conjunto de palabras hermēneuein y hermēneía como interpretāre e interpretātio (Mir, 1990), no hacen justicia a las palabras grie- gas, pues sólo recogen un aspecto de éstas: el de explicar/explicación, enfatizando con ello más la dimensión epistemológica de la hermenéutica, y poco o nada dicen de su dimensión ontológica. En breve, el latín recogió los significados 2 y 3 que menciona Palmer anteriormente.

En estos tres usos, concluye Palmer (1968, p. 31), "Algo extranjero, extraño, separado en el tiempo, el espacio o la experiencia se convierte en algo familiar, presente, comprensible. Algo que requiere representación, explicación o traducción es de algún modo 'traído a la comprensión', es 'interpretado'."

El texto de Cuestas Abad (1991, p. 16), mucho más reciente que el de Palmer, refuerza la etimología con estas palabras:

El verbo herméneuein (del que se derivan herméneia, herméneus, berméneutés, herméneutikos) significaba el acto de expresar, casi de 'revelar', un pensamiento antes imperceptible, de donde procede el significado de la herméneia como explicación o interpretación de un contenido mental dado. (...) Los visionarios, los portavoces de oráculos o incluso los poetas son llamados herméneutai en cuanto intérpretes de los dioses o desveladores de una voluntad divina configurada en mensajes. Según se siga una u otra trayectoria en el ducere, la tarea hermenéutica tratará de 'adentrar' desde el exterior del mundo o de 'extraer' desde el interior del pensamiento el ser ideal que se inviste de materialidad a través del lenguaje. 


\section{La hermenéutica: ¿Método de las ciencias del espíritu (Geisteswissenschaften)?}

La hermenéutica filosófica, literaria y teológica, de origen alemán e influenciada por el protestantismo decimonónico, especialmente a través de Schleirmacher, así como por la fenomenología y la filosofía existencial, es un modo de acercarse al texto y tratar de comprenderlo, y se inspira en el concepto griego de hermēneuein y hermēneía.

La hermenéutica es una práctica realizada mucho antes por el judaísmo alejandrino y por el cristianismo primitivo, que trataron de releer sus textos sacros, actualizarlos y que se volvieran algo vivo a lo largo del tiempo, que dijeran algo a creyentes que no eran contemporáneos al texto y a su situación; para esto tuvieron que hacer hermenéutica (Grech, 1986). Está claro que a partir de esta constatación -que encontramos en los evangelios, en San Pablo, en la Septuaginta, entre otras- se verifica que la hermenéutica tiene como modelo textual u obra a un texto que, principalmente y como afirma Palmer (1968) siguiendo a Gadamer (1999), puede estar separado de nosotros en su asunto, por el tiempo, el espacio, el lenguaje y por otras barreras que impiden su comprensión. Esto se aplica también a la comprensión del texto bíblico. La tarea de la interpretación debe ser el convertir algo cuyo significado era desconocido, distante y oscuro en algo real, cercano, inteligible. Los diferentes aspectos de este proceso de interpretación son vitales y esenciales para la literatura y la teología.
Así, entre texto y lector hay una distancia. La situación del texto y la del lector son distintas. Esto hace necesario eso que llamamos hermenéutica, una mediación de la comprensión, ayudar a inteligir, puesto que el texto y su mundo no son transparentes ni evidentes. Y debido a eso toda hermenéutica es situacional, contextual e histórica. Cada situación, cada época, relee el texto según su contexto y su realidad. De ahí que no haya una única interpretación, sino múltiples e históricamente condicionadas. En breve, no hay una verdad, no hay una interpretación dogmática; cada época construye su propia interpretación, pero no arbitraria, sino con base a lo que Gadamer (1999) llama tradición, una cadena de interpretaciones, y siendo conscientes de que trata de una interpretación posible y de que en todo interpretar hay precomprensiones, las que algunas veces son prejuicios. Este modo de entender la hermenéutica hace de la comprensión un proceso inacabado, infinito, abierto. En un momento Gadamer afirma que es un proceso no lineal o teleológico, sino que se desarrolla en espiral; por ello no se podría decir de un texto, por ejemplo, que se ha comprendido de manera definitiva: cada época construye su propia interpretación.

En no pocos libros de texto y en manuales se lee que la hermenéutica es un método científico, a la par de otros que también son referidos en los manuales mencionados. ¿Es cierto esto? Wilhelm von Dilthey (1949), en su Introducción a las ciencias del espiritu, parece haber sido el autor que inspiró a quienes piensan así, pero a su vez él se inspiró en Schleiermacher, el padre de la hermenéutica moderna. Cier- 
tamente, Dilthey protesta contra el enfoque del método positivista, que considera la unicidad del método científico, esto es, toda ciencia debe tener un único método, el positivo, planteado por Comte. Para Dilthey esta posición es legítima para un hemisferio del globo de la ciencia, para aquellas que él llama Naturwissenschaften (ciencias naturales); pero no lo es para el otro hemisferio: el de las humanidades. Estas necesitan su propio método, son autónomas; no hay posibilidades de analogía entre las ciencias naturales y las del espíritu en cuanto a su método, entre otras cosas.

Para Gadamer, en cambio, la hermenéutica no puede ser concebida como un método. Con claridad sostiene esto en su Verdad y método, pero también en una discusión con Habermas, quien acusaba al gran filósofo de la hermenéutica de conservatismo por el apego a la tradición como clave de la com- prensión y criticaba su método. Ante ello el profesor de Heidelberg responde que la hermenéutica no es un método.

Si no es método, ¿qué es la hermenéutica? En palabras de algunos estudiosos de Gadamer, ésta sería una especie de èthos, un modo de situarse frente a la obra; a lo que otros llaman un tacto para comprender la obra. En fin, no se trata de pasos metodológicos ni de un modo de construir conocimiento, sino de un modo de situarse frente al texto; leer la obra en su contexto y nuestro contexto; interpretar la obra y ser interpretados por ella. Todo esto, sin embargo, supone su análisis. Entonces, la hermenéutica implica el análisis, pero no se identifica con él; por ejemplo, no es igual a análisis literario. Todo esto implicaría, como dice Palmer (1968), que hay una diferencia entre la comprensión científica y la comprensión hermenéutica o histórica. 
AKADEMOS Enero-Junio 2020, n. ${ }^{\circ}$ 34, ISSN: 1995-4743

\section{Referencias}

1. Brown, R. and Schneider, S. (1993). Hermeneutics. Brown, R., Fitzmyer, J. and Murphy, R. (Eds.). (1993). New Jerome Biblical Commentary (NJBC), 1146-1165. New Jersey: Prentice Hall. 780-790.

2. Cuesta Abad, J. M. (1991). Teoría hermenéutica y literatura (el sujeto del texto). Madrid: Visor.

3. Palmer, R. E. (2002). ¿Qué es la hermenéutica? Teoría de la interpretación en Schleiermacher, Dilthey, Heidegger y Gadamer. Madrid: Arco Libros.

4. Grech, P. (1986). Ermeneutica e teologia biblica. Roma: Edizioni Borla

5. Gadamer, H. G. (1999). Verdad y método. Fundamentos de una hermenéutica filosófica. Salamanca: Ediciones Sígueme
6. Von Dilthey, W. (1949). Introducción a las ciencias del espíritu. México: Fondo de Cultura Económica

7. Liddell, H., and Scott, R. (1968). A Greek-English Lexicon. Oxford: Oxford University Press.

8. Heidegger, M. (1992). El Sery el tiempo. México: Fondo de Cultura Económica.

9. Bauer, W. (1979). A Greek-English Lexicon of the New Testament and other early Christian Literature. Chicago: The University of Chicago Press.

10. Ricoeur, P. (2001). La metáfora viva. Madrid: Trotta.

11. Mir, J. M. (ed.). (1990). Diccionario ilustrado latino español, español-latín. Barcelona: Bibliograf. 